\title{
Zubiri y la encarnación del Verbo de Dios (II)
}

\author{
Hugo Gudiel, \\ Centro de Reflexión Teológica, \\ San Salvador
}

En la primera entrega de este artículo presentamos, en el primer apartado, la concepción neotestamentaria de la encarnación. En el segundo apartado expusimos la precisión eclesial realizada en el tiempo del misterio de la encarnación. A continuación iniciamos, en el tercer apartado, con la primera sección centrada en la conceptuación teológica de la encarnación del Verbo de Dios ${ }^{1}$.

Esta segunda entrega de nuestro artículo concentra la atención en las dos últimas secciones que conforman este tercer y último apartado: la primera, en qué consiste la vida personal de Cristo, y la segunda en torno a la obra de Cristo.

\subsection{La vida personal de Cristo: su biografía}

Con el objeto de concretar un poco más la conceptuación zubiriana de la encarnación del Verbo de Dios, trataremos en esta segunda sección las siguientes tres cuestiones: en qué consiste la vida personal de Cristo, en qué consiste la encarnación biográfica, y cómo Cristo realiza su biografía.

\subsubsection{El problema: ¿en qué consiste la vida personal de Cristo?}

En primer lugar, es menester plantear y precisar el problema, pues este no es tan obvio como a primera vista pudiera parecer. Zubiri constata efectivamente que se trata de una cuestión que afecta a la teología y también a la exégesis neotestamentaria ${ }^{2}$. Pero tanto la teología como la propia exégesis se

1. Se trata de la primera entrega del artículo publicado en la Revista Latinoamericana de Teología 85 (2012), pp. 83-106; para ubicar esta segunda entrega, sugerimos la lectura de la introducción hecha ahí mismo, pp. 83-84.

2. El detalle de esta constatación exegética y teológica, ahí mismo (cfr. PTHC 290-292). 
han quedado a las puertas de lo que aquí se considera el problema esencial (cfr. PTHC 290-291).

El problema esencial radica en enfrentarse con la cuestión del "misterio mismo de la vida de Cristo" (PTHC 292). Esta expresión no se refiere a los "misterios de la vida de Cristo", sino a algo previo, es decir, a "la vida misma personal de Cristo sobre la tierra [que es] en sí misma un misterio". En qué consiste esa vida en cuanto misterio. He aquí el "problema que tiene que subyacer a toda consideración de los misterios de la vida de Cristo" (PTHC 293).

Se trata de habérselas con un problema teologal: "¿En qué consiste la razón teologal, el modo de ser de la vida personal de Cristo?". En otras palabras, se pretende indagar sobre el "modo de ser de la vida personal de Cristo", de su biografía. Esto se refiere ante todo y sobre todo a que él "se realizó como Verbo biográficamente, como Hijo de Dios". Y, entonces, hay que preguntarse por el sentido que tiene esa biografía para el propio Cristo, es decir, hay que averiguar lo que era la vida personal de Cristo para él mismo que la vivía (PTHC 293).

En segundo lugar, consideremos algunos actos de la vida de Cristo que contribuyen a comprender el "sentido" de la pregunta anterior (PTHC 293).

Por ejemplo, sabemos que Cristo ejecuta "actos psicofísicos", como comer y dormir, entre otros (PTHC 293).

Además, Cristo ejecuta actos de pensamiento y de voluntad. Efectivamente, Cristo "se asombra, pregunta, se entristece, algún día se enfada y lanza a los mercaderes del templo". ¿Qué significado tienen estos actos para el propio Jesús? (PTHC 294).

También sabemos que ejecuta actos en una sociedad. En efecto, Cristo "ha vivido en una sociedad" concreta, y esta tiene sus propios condicionamientos. Por ejemplo, por tener que cumplir sus padres una ley civil, "por haberse ido a empadronar, nació Cristo en Belén"4. Indudablemente, ahí hay unos condicionamientos sociales que tuvieron algún significado en y para la vida de Jesús (PTHC 294).

Pero, además, Cristo realizó actos religiosos. Recordemos por ejemplo que, teniendo aún doce años, Jesús "sube al templo de Jerusalén", y ahí "discute con los doctores e interpreta la Sagrada Escritura". ¿Qué pretendía Cristo al realizar este tipo de actos religiosos? (PTHC 294) ${ }^{5}$.

Siendo un poco mayor, Cristo también "se va a bautizar en el Jordán". ¿Qué significa esta acción para él, qué pretendía con ello? La respuesta a estas preguntas es compleja. Sin embargo, sí puede afirmarse que "el movimiento inicial de ir a

3. Para esos dos ejemplos, véase Mateo 9, 10-13 y Marcos 4, 35-41.

4. Cfr. Lucas 2, 1-7.

5. Cfr. Lucas 2, 41-50.

6. Cfr. Mateo 3, 13-17. 
recibir el bautismo de Juan en el Jordán fue iniciativa de Cristo”. ¿Qué significado tiene la ejecución de este acto de Jesús en el Jordán? (PTHC 295)7.

Finalmente, Cristo "en la cruz pronuncia una de sus siete palabras: 'Dios mío, Dios mío, ¿por qué me has abandonado?"” (Mc 15, 34). ¿De qué abandono se trata? (PTHC 295). Aquí se lee el abandono de Cristo en la cruz a la luz del Salmo 22, 4.23-32 (cfr. PTHC 295-296).

En todos los actos expuestos, surge la pregunta por la pretensión de Cristo y por el sentido que tiene cada uno de ellos para su propia vida. Por tanto, el problema queda "planteado por la vida misma de Cristo". Es decir, por "lo que esa biografía, como biografía de Hijo de Dios encarnado, significó para él personalmente”. Esto es lo que había que plantearse: “¿En qué consiste esta condición teologal de la biografía de Cristo" (PTHC 296).

No se trata de una cuestión ficticia, el cuerpo y la biografía de Cristo no son algo ficticio ( $c f r$. PTHC 297). Al contrario, el rigor de ese problema radica justo "en que se tenga una visión integral de lo que es la encarnación". En este contexto, merece la pena señalar que "el Verbo se encarnó no solamente en un individuo singular y socialmente determinado", sino precisamente "en una realidad humana biográficamente constituida". Es justo cuando arranca el problema: “¿En qué consiste esta encarnación biográfica?”. He aquí la cuestión que hay que afrontar y que queda de esa manera planteada. "El problema de lo que significó la realización biográfica del Hijo de Dios, en tanto que biográfica, para el propio Hijo de Dios". Es justo el problema de la vida personal de Cristo que a continuación vamos a estudiar (PTHC 298).

\subsection{2. ¿En qué consiste la encarnación biográfica del Verbo?}

En primer lugar, para responder adecuadamente a esta pregunta, veamos en los dos siguientes pasos qué se entiende por biografía.

Ante todo, la biografía consiste en que la realidad sustantiva de todo ser humano se va realizando en el transcurso de los actos que componen su vida. La biografía que el hombre va realizando es algo que pertenece al acto segundo. El acto primero es mi realidad sustantiva; el acto segundo, en cambio, es lo que hago de mí. Lo que hago de mí es precisamente "mi ser [de lo] sustantivo, mi Yo". La biografía es ante todo la construcción de "mi ser [de lo] sustantivo". Este ser no está yuxtapuesto a mi realidad sustantiva, sino que "cuando yo tengo mi vida, tengo un estado vital determinado, tengo la vivencia en la suidad". "Eso que yo he hecho de mí, lo hago justamente de mí, es decir, revierto por vía de identidad a mi propia realidad sustantiva desde la que he ejecutado mi propio ser [de lo] sustantivo" (PTHC 299).

7. Cfr. PTHC 309. 
La segunda cosa que cabe destacar es que esta identidad no es una identidad quiescente (estática), sino que más bien consiste en que "en ese ser [de lo] sustantivo en que yo me he realizado, me estoy poseyendo a mí mismo". En esto consiste precisamente vivir: "Vivir es poseerse". . En consecuencia, "la vida es autoposesión y la biografía es justamente la construcción [...] del ser [de lo] sustantivo", en virtud del cual "me estoy autoposeyendo" (PTHC 299)9.

Ese autós de la autoposesión tiene tres particularidades ${ }^{10}$. El hombre puede poseerse, por ejemplo, diciendo: me como una manzana. Aquí hay un autós que está vivido en una forma "medial". Si en cambio expreso: es $m i$ dolor de muelas, el autós "está vivido en una forma de mî". Finalmente, también puedo afirmar: "yo hago esto, soy Yo el que lo hace. Entonces tenemos esta forma radical y expresa en que consiste el Yo". Por tanto, el ser humano "puede tener esta vivencia de autoposesión en el me, pura y simplemente porque es un... [autós]. Y en esto consiste la vivencia" (PTHC 300).

En este contexto, caben dos aclaraciones. Ante todo, ninguna de estas tres fases (el $m e$, el $m i$ y el Yo) añade nada en realidad a la fase anterior ( $c f r$. PTHC 300). Ciertamente, no le añade "propiedades reales, pero evidentemente le compone un cierto modo de poseerse a sí mismo". En efecto, "las mismas propiedades están poseídas de un modo distinto. Es la misma suidad inicial vivida en forma distinta". Cabe aclarar también que "esta triplicidad de términos es realmente fundante y, además, discursiva. El Yo se funda en el $m i$, y el $m i$ en el $m e$ " (PTHC 301).

He aquí, pues, la "esencia de toda biografía. Es la autoposesión en esta forma dinámica en la que se va pasando de un $m e$ a través de un $m i$ a un Yo". Este Yo es el que precisamente "revierte en forma de identidad autoposesiva a aquella realidad sustantiva que compone mi propia realidad individual, mi realidad en suidad" (PTHC 301).

En segundo lugar, la propia persona de Cristo en cuanto Verbo encarnado participa de lo anteriormente expuesto sobre la biografía ${ }^{11}$. En efecto, primaria

8. Vida no es "auto-moción", sino que, en rigor, "es un modo de 'auto-posesión', esto es, ser en realidad y sentirse un autós" (IRE 211). Pero el hombre es autós de un modo singular: "Siendo no solamente sustantividad propia, sino siendo su propia realidad en cuanto realidad". En el ser humano se trata de un autós en que se pertenece "formal y reduplicativamente por su carácter mismo de realidad. Se pertenece a sí mismo como realidad: es persona. Persona es formal y reduplicativa suidad real" (IRE 212).

9. "La vida humana es autoposesión en decurrencia. Y esta autoposesión es justo la esencia de la autobiografía: un proceso de autoposesión de su propia realidad" (SH 18).

10. Véase también PTHC 266-267.

11. "La encarnación de Cristo es integral; esto significa que es biológica e histórica, social y a la vez que individual, metafísica a la vez que biográfica. Zubiri ha 
y básicamente lo que "Cristo hace en su vida es su ser [de lo] sustantivo como Hijo encarnado de Dios". Recordemos que para Zubiri, no todas las acciones de Cristo son teándricas, sin embargo "su Yo, su me y su $m i$ son constitutivamente teándricos". Es precisamente el "acto segundo de lo que es en acto primero como Hijo de Dios" (PTHC 301).

Ahora bien, justo en esta "autoposesión como Hijo de Dios [Cristo] está sometido a esta condición biográfica de todo hombre, que es que puede sentirse, saberse real y efectivamente Hijo de Dios" en la forma de un $m e$, de un $m i$ y de un Yo. "Es la misma suidad teándrica vivida en tres formas, que a una tienen su 'suidad". Y es que el Yo de Jesucristo no es algo dado o innato, es construcción biográfica (PTHC 301) $)^{12}$.

Por tanto, la biografía de Jesucristo, como la de cualquier ser humano, consiste en conseguir un "ser [de lo] sustantivo por las circunstancias, externas e internas, en que esa realidad sustantiva está construyendo su vida" (PTHC 302-303).

En este contexto, se cita el Evangelio de san Lucas 2, 52, según el cual Cristo "crecía en sabiduría, en estatura y en gracia delante de Dios y de los hombres"13. Este crecimiento de Cristo ante Dios significa, a juicio de Zubiri, "un crecimiento en la configuración de su ser [de lo] sustantivo". En otros términos, quiere decirse que la "personeidad de Cristo, desde el primer momento de su concepción, ha sido consustancial a Dios (por lo menos, hipostáticamente consustancial a él)". En cambio, la personalidad de Cristo "no ha sido consustancial", porque su personalidad ha tenido que ir construyéndosela en el transcurso de su vida. He aquí lo que pone de manifiesto el anterior texto de san Lucas (PTHC 303).

Apoyados en lo dicho sobre la encarnación biográfica de Cristo, vayamos al tercer y último aspecto de la vida personal de Cristo.

\subsection{3. ¿Cómo realiza el hombre su biografía?}

Para responder procesualmente esta pregunta vamos a considerar dos momentos: la fundamentalidad del ser humano y la fundamentalidad del ser de lo sustantivo de Cristo ${ }^{14}$.

subrayado esta última dimensión con especial perspicacia” (O. González de Cardedal, Cristología, p. 394).

12. $C f r$. PTHC 268.

13. Sobre este versículo del Evangelio de san Lucas, véase la nota exegética de J. A. Fitzmyer, El Evangelio según san Lucas, II, Madrid, 1987, pp. 291-292.

14. Cfr. O. González de Cardedal, Cristología, op. cit., pp. 482-483; ahí, el teólogo recoge estos dos momentos de la biografía que Zubiri señala. 


\section{a. La fundamentalidad del ser humano}

Ante todo, precisemos que el hombre al ejecutar sus actos está con las cosas $\mathrm{y}$, con ellas y entre ellas, aquello en que formalmente está es en la realidad. Las cosas pueden cambiar en el transcurso de las vicisitudes, pero lo que no cambia es el hecho inexorable de que el ser humano esté y tenga que estar en la realidad (cfr. PTHC 303).

Esta realidad es, ante todo, la ultimidad de las cosas y de la realidad humana; lo último y radical de las cosas es que son reales. Además, "esta realidad es la raíz y el cuadro donde se inscriben últimamente las posibilidades de que el hombre pueda disponer para ejecutar su vida". La realidad en cuanto realidad es su última posibilidad. Finalmente, esta realidad es aquello que impele al hombre a "ser". Es inevitable que el hombre tenga que ir haciéndose; a ello le impele la realidad (PTHC 304).

La rigurosa unidad de la realidad en cuanto última, posibilitante e impelente es lo que constituye la "fundamentalidad" de la persona ${ }^{15}$, en tanto que realizada en su ser [de lo] sustantivo. Esta fundamentalidad con sus tres caracteres se manifiesta como el "poder de lo real" ${ }^{\prime}$. Y este poder de lo real es aquello que "constituye la fundamentalidad" de la vida humana, aquello que impele ineludiblemente al hombre a hacer su biografía (PTHC 304).

Pues bien, Cristo no está al margen de esta condición, más bien la "sublima". Aquí cabe recordar que el poder de lo real es la "deidad"17. Deidad para Zubiri es "el carácter con que las cosas dejan traslucir aquella realidad absoluta en la que se encuentran apoyadas". En la persona de Cristo la "fundamentalidad de su vida se apoya en el poder de lo real". Solo que en su caso particular "eso real está vivido de una manera directa, inmediata, como manifestación de la procesión iniciante con que la divinidad ha creado las cosas". En efecto, en el caso de la persona de Cristo hay una coincidencia extraordinaria "entre lo que las cosas son como reales y lo que son como término de la voluntad de su Padre" (PTHC 304).

Por tanto, la fundamentalidad de la existencia singular de Jesucristo consistió esencialmente en que, al ocuparse Cristo de las cosas reales, estas eran propiamente la "voluntad misma de su Padre". Tal voluntad no se realiza fuera de las cosas reales, sino en ellas: "Son las cosas mismas las que constituyen la voluntad de su Padre". En consecuencia, el poder de lo real con que Cristo va "cons-

15. Cfr. HD 81-84 (PTHC 304, nota 1). Véase una síntesis de esas páginas en H. C. Gudiel García, La fe según Xavier Zubiri, pp. 78-79.

16. Cfr. HD 139-144. Véase también nuestra síntesis de esas páginas en H. C. Gudiel García, La fe según Xavier Zubiri, op. cit., pp. 100-102.

17. Cfr. HD 156-157; PFHR 43-53 (PTHC 304, nota 2). Una síntesis de las páginas del PFHR 43-53, en el ámbito de las religiones, en H. C. Gudiel García, La fe según Xavier Zubiri, op. cit., pp. 200-205. 
truyendo su ser [de lo] sustantivo no es otra cosa sino esta voluntad del Padre, con que de una manera libre, pero real y efectiva, ha hecho que las procesiones trinitarias terminen inicialmente ad extra" (PTHC 305).

Pero esto que se ha dicho sobre la fundamentalidad del ser humano no es suficiente para el tema que nos ocupa. Es menester precisarlo un poco más desde el punto de vista del ser de lo sustantivo de Cristo. Es lo que haremos a continuación.

\section{b. La fundamentalidad del ser de lo sustantivo de Cristo}

¿En qué consiste para Cristo la fundamentalidad de su propia realidad como momento de su ser de lo sustantivo? En esa cuestión se implica la "última raíz de lo que significó la biografía personal de Cristo para él”. Zubiri responde esa pregunta centrando su atención en la religación subsistente, la revelación subsistente y la sacralidad subsistente (PTHC 305) ${ }^{18}$.

b.1. Religación subsistente. Ante todo, Cristo es la religación subsistente ${ }^{19}$. Para explicar este concepto, aquí se parte de lo que san Pablo dice a los Filipenses: Cristo "se hizo obediente hasta la muerte, y muerte de cruz. Por lo cual Dios le exaltó y le dio un nombre que está por encima de todo nombre" $\left(\right.$ Flp 2, 8) ${ }^{20}$. Zubiri admite que el hecho de que san Pablo diga que Cristo era "obediente" es ya bastante, y es verdad. Sin embargo, precisa inmediatamente que esa obediencia de Cristo "no constituía la dimensión radical de su fundamentalidad". La razón de ello consiste en que "todo acto de obediencia presupone alguien quien manda y alguien que es capaz de ser mandado". Es aquí donde surge el problema fundamental: “¿En qué consiste la capacidad de ser mandado que Cristo tenía como Hijo de Dios?” (PTHC 306).

En esta perspectiva hay que considerar que hay una "condición interna", en virtud de la cual la fundamentalidad pertenece al propio ser humano. Es justo

18. Una síntesis de esos tres conceptos en O. González de Cardedal, Cristología, op. cit., p. 483 .

19. 'Zubiri recurre al clásico término de la 'subsistencia' no por dependencia de la escolástica, sino porque los padres capadocios ya habían realizado el esfuerzo titánico de 'despojar al término hipóstasis de su carácter de puro hypokeímenon, de su carácter de subjectum y de sustancia para acercarlo a lo que el sentido jurídico de los romanos había dado al término persona, a diferencia de la pura res de la cosa (HD 323)"; en J. Sáez Cruz, La accesibilidad de Dios, Salamanca, 1995. Véase también PTHC 122-124. Al hablar de la vida trinitaria, Zubiri afirma que "se trata de tres subsistencias o suidades distintas" (PTHC 212).

20. El texto de Filipenses 2, 8-9 dice que Cristo "8se rebajó a sí mismo, haciéndose obediente hasta la muerte y una muerte de cruz ${ }^{9}$. Por eso Dios lo exaltó y le otorgó el Nombre que está sobre todo nombre" $(N B J)$. 
la religación ${ }^{21}$. Y porque el hombre está religado es por lo que puede tener "obligaciones" 22 . En el caso concreto de la persona de Cristo, habría que afirmar, además, que solo "porque él está incurso en la procesión generante del Verbo, su realización biográfica es justamente la religación subsistente" ${ }^{23}$. Y por serlo es por lo que Cristo puede tener "obediencia". En este sentido, "la fundamentalidad pertenece al ser propio y personal de Cristo precisamente porque es religación subsistente" (PTHC 306).

La religación no es una propiedad de la naturaleza, sino de la persona, es una dimensión personal. Por tal razón, la religación "se va plasmando en una serie de actos que, en definitiva, envuelven uno solo, que es acatar" 24 . Y justo en "este acatamiento subsistente, en que consistía la biografía de Cristo en tanto que religada, es en lo que está el secreto de qué significaron para él los actos religiosos que realizó en su vida" (PTHC 306).

21. Sobre este concepto clave en la perspectiva del problema teologal del hombre en Zubiri, véase HD 92-99; también, nuestro artículo "Realidad humana y religación en Zubiri y su recepción en Ellacuría", en Revista Latinoamericana de Teología 78 (2009), pp. 299-334; véase además A. Torres Queiruga, Filosofía de la religión en Xavier Zubiri, pp. 49-84.

22. $C f r$. HD 93-94.

23. Cfr. HD 333.

24. Entregarse a Dios es ir a Él en cuanto realidad absolutamente última. Desde este aspecto, la entrega cobra carácter de acatamiento. Ahora bien, acatar no es propiamente "obedecer". Lo radical del acatamiento consiste más bien en "esa especie de reconocimiento de lo relativo que soy frente a la persona absolutamente absoluta que es Dios. Es como un desaparecer ante Dios". Es precisamente lo que expresa el término latreúo, es decir, "adorar". Adorar es efectivamente "acatar la plenitud insondable de esta última realidad". Cuando el hombre va a las cosas reales, se inclina ante la realidad de ellas " $\mathrm{y}$ en ellas acata a Dios personalmente transcendente". A la donación de la realidad de Dios, pues, "corresponde el hombre con el acatamiento al donante: es la esencia de la adoración personal" (HD 199); en H. C. Gudiel García, La fe según Xavier Zubiri, op. cit., p. 127.

En esta perspectiva y a mi juicio, el acatamiento significa ir a Dios en cuanto Dios, es decir, significa reconocer y entregarse a Dios en cuanto realidad absolutamente absoluta, pero precisamente para que el ser humano pueda ser en Dios. En otras palabras, para que pueda realizarse plenamente como realidad relativamente absoluta, es justo lo que le corresponde. Por tanto, se trata de ser en Dios y no a espaldas de Él o, peor aún, sustituyéndole por todo tipo de ídolos tanto antiguos como modernos que constantemente acechan la vida personal y social de los seres humanos. En definitiva, acatar significa dejar a Dios ser Dios, pero justo para que yo pueda ser en Dios. De lo contrario, es imposible que el hombre se realice plenamente. Es que Dios no es un obstáculo para la vida del hombre, sino más bien quien la plenifica y le da toda la posibilidad para su plena realización. 
Efectivamente, Cristo "estaba acatando la voluntad de Yahvé; aceptó la religión de Yahvé porque era precisamente la religión del Padre". Justo porque en esa religión del Padre "se plasma el acatamiento en que Cristo consiste constitutivamente, en tanto que religación subsistente" 25 . Desde esta perspectiva, la biografía de Cristo fue para él mismo el "despliegue de su constitutiva y subsistente religación". Por tanto, la encarnación "tuvo como término formal precisamente una realidad humana biográfica". Y justo porque el Verbo se realizó en una "humanidad biográfica, es por lo que el Verbo encarnado, el Hijo de Dios, es constitutivamente religado: es la religación subsistente". Por tal razón, este es un concepto "teologal" (PTHC 307).

Esta realización humana de la biografía es fundamentalmente "experiencia". Por experiencia aquí se entiende la "probación física de realidad"26. En el caso de la persona de Cristo, "fue una experiencia de la religación subsistente en que él consiste. Una religación subsistente que él fue probando por experiencia a lo largo de su vida". Efectivamente, Cristo "realizó de una manera experiencial en qué consiste ser Hijo de Dios" encarnado (PTHC 307).

Los mismos Evangelios testimonian que Cristo no quiso actuar de modo contrario a esta experiencia ( $c f r$. Mc 15, 29-32; Mt 4, 1-11). En efecto, él quiso "saber por experiencia lo que es ser religadamente Hijo de Dios". Y en esa experiencia él fue consiguiendo las "posibilidades para poder hacer su ser personal y, en este caso, el ser divino de Cristo" (PTHC 308). Es lo que nos introduce en el segundo concepto.

b.2. Revelación subsistente. Además de religación subsistente, Cristo es la revelación subsistente ${ }^{27}$. Para clarificar adecuadamente este segundo concepto

25. No cabe ninguna duda de que el paradigma y la plenitud del acatamiento se realiza en Jesucristo, el Hijo de Dios, quien hasta el último momento de su vida histórica se entregó a la voluntad de esa realidad última: su abba. El acatamiento, por tanto, tiene que ser consecuencia de esa experiencia real y espiritual de intimidad con nuestro Padre, Dios, que es a quien encontramos precisamente en la revelación de Jesús el Cristo. Sobre la "confianza" de Jesús con su abba, véase J. Sobrino, Jesucristo liberador. Lectura histórico-teológica de Jesús de Nazaret, pp. 251-253. Puede verse también F. X. Durrwell, Nuestro Padre. Dios en su misterio, Salamanca, 1990.

26. Se trata de un concepto central en el pensamiento maduro de Zubiri, y que puede verse con detalle en IRA 222-257 ( $c f r$. PTHC 307, nota 1).

27. Cfr. PTHC 317. Sobre "la revelación en Zubiri", véase A. Torres Queiruga, Filosofía de la religión en Xavier Zubiri, Valencia, 2005, pp. 85-99. A propósito del tratamiento que Zubiri hace del tema de la revelación, Torres Queiruga constata una feliz coincidencia con el filósofo, afirmando que "acaso por afinidad profunda y en todo caso por azar biográfico, se trata de un tema en el que yo mismo he sido el primer sorprendido por mi casi total coincidencia con la propuesta zubiriana" (ibid., p. 86). La exposición sistemática de Torres Queiruga sobre el tema, en Repensar la revelación. La revelación divina en la realización humana, Madrid, 2008. 
es menester precisar, ante todo, que la "experiencia humana es siempre una experiencia manifestativa. Es la probación física de realidad y lo real se me manifiesta". Por manifestación aquí se entiende la "actualización de la riqueza de lo real en un despliegue de uno o de otro orden” (PTHC 308).

En el caso de Cristo cabe notar que su vida entera ha sido la "manifestación de lo que es él como Hijo y, por consiguiente, de lo que es el Padre en tanto que Padre" 28 . Es decir, Cristo es la revelación subsistente y, precisamente por serlo, "esta revelación es un dato biográfico, es un momento experiencial a lo largo de la vida" (PTHC 308).

Efectivamente, la "experiencia de la vida de Cristo ha tenido, desde el Jordán hasta la cruz", varias etapas en las que se ha sabido progresivamente Hijo de Dios (PTHC 309).

En primer lugar, se pone de relieve que cuando Cristo "llegó al Jordán lo que supo él es justamente que era Mesías. Es decir, que iba a hacerse solidario de una humanidad pecadora" 29 . En efecto, Cristo "no tenía pecado, pero su bautismo fue el acto en que para él se constituyó la explicitud de un me en forma de Yo mesiánico" (PTHC 309).

En esta perspectiva se añade que la encarnación es también la "realización en un individuo biográficamente considerado, solidario en su biografía con una humanidad pecadora". En esto consiste precisamente el acto de Cristo del Jordán: "No saberse él pecador ni decirle nada que no supiera (al fin y al cabo, tenía un me), pero explicitarlo en un primer grado de riqueza” (PTHC 309).

En segundo lugar, y poco tiempo después, Cristo "va a ejercer su misión mesiánica en Galilea"; allí tuvo la experiencia real y verídica del "fracaso" 30. Cristo no logró su pretensión. "Y este fracaso hizo que él tuviera que pensar en que ser el Mesías de una humanidad pecadora tendría que serlo no limitándose al mundo de Israel ni apoyándose en él, sino estando de antemano abierto a todos, incluso a los gentiles" (PTHC 309).

A continuación, en tercer lugar, sigue una nueva etapa: Cristo "sabe que le van a aprender y le van a matar". Por tanto, él "acepta" su muerte. En esa realidad del "acepta" es donde se pone de manifiesto su "obediencia". Esto no significa autoimposición. Propiamente, Cristo ha venido a este mundo a redimir a

28. Cfr. H. C. Gudiel García, La fe según Xavier Zubiri, op. cit., pp. 122-124; PFHR 241-253.

29. Cfr. Marcos 1, 9-11; Mateo 3, 13-17. Véase, además, O. González de Cardedal, Cristología, op. cit., pp. 40-42.

30. Sobre este "fracaso" llamado "crisis de Galilea", véase J. Sobrino, Jesucristo liberador, op. cit., pp. 259-262; también O. González de Cardedal, Cristología, op. cit., pp. 79-81; y C. H. Dodd, El fundador del cristianismo, p. 161. 
la humanidad. Fue la obediencia a su Padre lo que llevó al Hijo de Dios a aceptar "incluso la muerte si hacía falta. Y la aceptó con obediencia" (PTHC 310).

Finalmente, en cuarto lugar, Cristo no solo sabe que va a morir, también descubre "que va a morir por la expiación de esa humanidad pecadora de la que se hizo solidario en el Jordán: es el carácter expiatorio del sacrifico de la cruz". Es en ese momento en el que Cristo "se siente en su soledad total como Hijo de Dios. Como un Hijo de Dios cuyo Verbo se realiza en una humanidad cargada de pecado de la que es solidario y por la que va a morir en expiación de sus pecados, pero sin abdicar de su carácter de Hijo de Dios". Al contrario, llevándolo "desde la cruz". En esta perspectiva, el sacrificio de Cristo en la cruz no está en la mera crucifixión, sino en la "oblación interna con que él ofreció su vida, que le quitaban, al Padre" (PTHC 310).

En el contexto de estas etapas surge la pregunta: “¡Y cómo aconteció esta biografía, este progresivo esclarecimiento de lo que eran las condiciones biográficas de Cristo como Hijo de Dios?" (PTHC 310).

Zubiri responde a la pregunta anterior afirmando que "no sabemos lo que aconteció en la intimidad de Cristo". Lo que sí puede afirmarse con toda seguridad es que, en su intimidad, Cristo "reflexionó sobre lo que acontecía en la tierra y lo que eran las cosas que le rodeaban". En esa intimidad de la persona de Cristo es donde se conjugan unitariamente lo que "viene de Dios y lo que viene de la reflexión humana realizada dentro de las luces que vienen de Dios". En esa intimidad es donde Cristo va viendo, en modo cada vez más explícito, la "riqueza en que consiste, en acto segundo, el ser la verdad real de lo que en acto primero es como encarnación del Verbo: Cristo, religación subsistente y revelación subsistente" (PTHC 311).

b.3. Sacramento subsistente. Pero Cristo no solo es religación y revelación subsistente, también es sacramento subsistente ${ }^{31}$. En este tercer concepto se consideran dos elementos.

En primer lugar, la sacralidad. En efecto, la humanidad de Cristo "por ser la humanidad del Verbo encarnado es sagrada" 32 . Es decir, es la "sacralidad constitutiva". Es lo que significa etimológicamente el término "sacramentum: sacralidad" (PTHC 311).

Esta sacralidad implica, en segundo lugar, que para el propio Cristo sus mismas circunstancias humanas fueron objeto de una reflexión. En consecuencia, Cristo tenía que ver en sus propias vicisitudes humanas los "signos de la voluntad de su Padre". Esta "sacralidad en forma de signo" es lo que en rigor constituye para Zubiri un sacramento (PTHC 311).

31. Cfr. PTHC 59-60.

32. Cfr. PFHR 18-28. 
En suma, Cristo también fue sacramento subsistente. Por esa razón, más que prodigios, propiamente Cristo hizo "signos" ${ }^{33}$. Y lo que pidió al hacerlos no fue un argumento sobre los prodigios, sino precisamente una "adhesión personal" (PTHC 312) ${ }^{34}$.

Desde esa perspectiva, comprendemos, entonces, que el secreto mesiánico ${ }^{35}$ para Cristo fue ante todo la condición interna de su propia biografía. "Cristo ha ido haciendo su ser personal como ser mesiánico y, dentro de él, ha ido esclareciendo aquello en que consiste en acto segundo la realidad de ser Hijo de Dios en su perfecta intimidad" (PTHC 312).

En resumen, la religación subsistente, la revelación en acto y la sacramentalidad subsistente, unitariamente considerados, son los tres conceptos que, a juicio de Zubiri, constituyen precisamente el "sentido último y radical de lo que fue la biografía de Cristo para Cristo mismo que la vivió, a saber: la experiencia teologal, humana y biográfica de su propia filiación divina" (PTHC 312).

En efecto, Cristo quiso saber en modo humano "lo que era necesitar de Dios, saber lo que era pedirle ayuda". En definitiva, quiso saber "lo que es ser humanamente Hijo de Dios". Este es, para el autor, el "sentido de la biografía de Cristo". Desde ahí puede recordarse nuevamente el texto del Evangelio de Lucas 2, 52: lo que Cristo hacía era enriquecer, progresivamente en experiencia teologal, "lo que era la plenitud biográfica de lo que le iba aconteciendo humanamente como Hijo de Dios" (PTHC 312).

Pues bien, ser Hijo de Dios consiste fundamentalmente en que Jesucristo vaya realizando, "por experiencia interna, su propia biografía en tanto que Hijo de Dios” (PTHC 312-313).

Esa biografía de la persona de Cristo en cuanto Hijo de Dios es la que se va a transmitir por una tradición viva a sus seguidores inmediatos. Pero ahí no solo

33. Sobre este punto, véase H. C. Gudiel García, La fe según Xavier Zubiri, op. cit., pp. 297 a 260. Sobre los milagros como "signos", véase R. Latourelle, Milagros de Jesús y teología del milagro, pp. 315-330.

34. Una explicación de la "adhesión personal" como característica de la dimensión humana de la fe, en H. C. Gudiel García, La fe según Xavier Zubiri, op. cit., p. 134; y sobre la dimensión cristiana de la misma, puede verse ibid., pp. 324-326.

También Juan Pablo II, en su carta encíclica Veritatis splendor, ha subrayado lo radical de la adhesión del hombre a la persona de Jesús. En efecto, no se trata "solamente de escuchar una enseñanza y de cumplir un mandamiento, sino de algo mucho más radical: adherirse a la persona misma de Jesús, compartir su vida y su destino, participar de su obediencia libre y amorosa a la voluntad del Padre. El discípulo de Jesús, siguiendo, mediante la adhesión por la fe, a aquel que es la Sabiduría encarnada, se hace verdaderamente discípulo de Dios (cfr. Jn 6, 45)" (VS 19).

35. Cfr. PTHC 270-271. 
se transmite lo que Cristo era, sino también su vida interna en intimidad con su Padre. La transmisión de esta vida fue justo el origen de la obra de Cristo: el cristianismo ( $c f r$. PTHC 313). Es lo que tenemos que escudriñar a continuación.

\subsection{La obra de Cristo: el cristianismo ${ }^{36}$}

Analizadas en los dos apartados anteriores la identidad y la biografía de Jesucristo, Hijo de Dios, veamos en seguida la obra de Cristo.

La forma adecuada de enunciar este tema consiste en afirmar que "la razón formal de la encarnación es justamente la deiformidad humana" ${ }^{37}$. En efecto, los seres humanos entran en el designio de la encarnación, "pero no en tanto que humanidad pecadora, sino en tanto que humanidad deiforme" 38 . Y por eso, la encarnación es un "dar de sí ad extra en la criatura deiforme”. En este sentido, la "encarnación tuvo lugar como la fundamentación de esta deiformidad. Y como esta fundamentación y esta fundación es [...] la plasmación de la propia religación,

36. Sobre este tema, y centrándose en los sacramentos, véase el trabajo de J. M. Millás, "Zubiri y los sacramentos", Gregorianum 82/2 (2001), pp. 299-323.

37. "En el Zubiri maduro, deiformación es el tercer momento del despliegue del problema teologal del hombre, después de la religación y la religión. La deiformación acontece según el cristianismo. La deiformación es un esbozo teológico propio del cristianismo, según el cual las cosas [...] consisten ulteriormente en ser deiformes. Si las cosas reales en cuanto creadas son Dios ad extra, en cuanto elevadas al orden sobrenatural [...] consisten en 'ser como Dios'. Deiformidad consiste en ser como Dios. En el caso de las personas humanas, esta deiformación [...] desde una inteligencia sentiente, es probada realmente como la presencia de Dios transcendente 'en' su personeidad, que configura deiformemente por donación de su absolutividad, es decir, como la presencia constituyente de la realidad persona humana en cuanto relativamente absoluto" (J. Sáez Cruz, La accesibilidad de Dios, p. 289). Véase también en J. L. Cabria Ortega, Relación Teología-Filosofía en el pensamiento de Xavier Zubiri, pp. 308-311.

38. "La deiformación es, también, algo más radical que la salvación. Para Zubiri, el cristianismo no sería primariamente una religión de salvación. Es decir, no consistiría primariamente en una respuesta a las indigencias y a los males de la vida humana, sino al revés. La deiformación que el cristianismo ofrece sería el fundamento de la salvación ( $c f r$. DHC 4-5). La salvación no sería otra cosa que el dar a la deiformación primaria que el hombre tiene como criatura la capacidad de inscribirse dentro del poder de Dios librándose del poder del mal objetivado en el mundo ( $c f r$. DCH 286). $\mathrm{Y}$ es que, para Zubiri, el pecado original no consiste en ningún tipo de epidemia hereditaria, sino en un pecado de origen moral que ha adquirido poder en el mundo social e histórico de los hombres ( $c f r$. DHC 277 y ss.). Ahora bien, la inscripción del hombre bajo el poder de Dios es algo que se funda en su deiformidad primaria y radical. La deiformación es, en este sentido, tanto el fundamento de la salvación como el fundamento de la revelación" (A. González, La novedad teológica de la filosofía de Zubiri, p. 27). 
quiere decirse que la posición de Cristo en la creación es idénticamente la fundación de una religión" (PTHC 315).

Dicho lo anterior, vamos a considerar en esta sección tres aspectos: qué es fundar, la acción fundante y las repeticiones de las acciones de Cristo.

\subsubsection{Fundar para Cristo es hacer cristianos}

El significado de la expresión fundar se desarrolla aquí en dos momentos: desde la realidad humana y desde la realidad de Cristo.

En primer lugar, desde el punto de vista de la realidad humana, "Cristo funda la religión para la deiformación del hombre" (PTHC 315) 39. Para explicar qué se entiende por fundar, Zubiri recuerda algunas de sus ideas expuestas sobre el hombre en general.

Ante todo, dice que el hombre "es una realidad sustantiva que tiene que hacer su Yo". En otras palabras, el hombre tiene que hacer su personalidad, "su ser [de lo] sustantivo relativamente absoluto" (PTHC 316).

Además, en este hacer su Yo, el ser humano se encuentra "dominado y posibilitado por el poder de lo real, en forma de religación". La religación pertenece a su dimensión personal, en tanto que "va a realizar su propio ser [de lo] sustantivo" (PTHC 316).

Cabe señalar también que es precisamente la religación la que lleva al hombre a la "admisión de la realidad absolutamente absoluta y personal que es Dios" (PTHC 316) ${ }^{40}$.

Y la entrega del hombre entero a esta realidad absolutamente absoluta de Dios en cuanto realidad verdadera, es justo aquello que constituye la $f e^{41}$. Zubiri termina afirmando que "la configuración del Yo entero, en esta fe, es aquello en que formalmente consiste la religión" ${ }^{\text {"42 }}$. Esto es lo primero que hay que tomar en consideración para poder responder adecuadamente a la cuestión de "qué fue fundar la religión, por parte de Cristo". Con lo cual se pone de manifiesto que la

39. Cfr. ibid., p. 3.

40. Sobre la justificación zubiriana de la realidad de Dios y algunos de sus caracteres, véase nuestro trabajo H. C. Gudiel García, La fe según Xavier Zubiri, op. cit., pp. 99-118.

41. Desde una perspectiva humana, la fe es formalmente "una entrega o adhesión personal, firme y opcional a una realidad personal en cuanto verdadera". En último término, la fe es apropiarnos esa "atracción" en virtud de la cual "la verdad personal de Dios nos mueve hacia Él. En esta fe consiste en definitiva "el acceso radical del hombre a Dios (HD 221)"; en H. C. Gudiel García, La fe según Xavier Zubiri, op. cit., p. 136.

42. Sobre la dimensión religiosa de la fe, véase PFHR 85-113 (cfr. PTHC 316, nota 1). 
religión es una configuración intrínseca "del ser [de lo] sustantivo en su entrega a Dios" (PTHC 316) ${ }^{43}$.

En segundo lugar, desde el punto de vista de la realidad de Cristo, conviene preguntarse de entrada: ¿en qué consistió la fundación del cristianismo? Ante todo, hay que decir que la "fundación del cristianismo fue una acción personal de Cristo" (PTHC 316) ${ }^{44}$.

Se trata evidentemente de una acción personal realizada por Cristo. En consecuencia, afirmar que él es la deiformidad del ser humano es igual a afirmar que él se ha "encarnado en, por y para esta deiformidad". Por consiguiente, al Yo formalmente teándrico de Cristo le corresponde "fundar la religión" (PTHC 317).

Naturalmente, fue el Verbo encarnado quien logró esta decisión en su intimidad total. Esta intimidad absoluta era "revelación subsistente". La revelación no es algo extrínseco a la realidad humana de Cristo, no es algo que le viniese como "dictado" ad extra del Padre. Por revelación, Zubiri entiende sencillamente la "reflexión humana que Cristo realizaba sobre las situaciones de su vida, sobre los sucesos de ella y sobre las cosas que le rodean, a la luz, que solamente él tenía, de la voluntad del Padre, de la cual la realidad de las cosas es expresión formal para Cristo" (PTHC 317) ${ }^{45}$.

Ese saber humano-divino que Cristo fue adquiriendo en su "intimidad" es indivisible, y por lo mismo tiene que ser unitariamente considerado (PTHC 317). Fue ciertamente un saber infuso. Pero este no puede ser entendido como un mero "dictado" externo que le viene del Padre, sino propiamente como un saber adquirido, esto es, como un saber "cobrado" 46 . Cobrado, naturalmente, en la singular y peculiar "intimidad que Cristo tuvo con su Padre, en la intimidad de su experiencia de la filiación divina” (PTHC 318).

43. Sobre la dimensión humana, religiosa y cristiana de la fe, véase nuestro trabajo H. C. Gudiel García, La fe según Xavier Zubiri, op. cit.

44. Conscientemente, Zubiri deja de lado el eterno problema de "si Cristo tuvo o no la intención de fundar una Iglesia" (PTHC 316-317).

45. Cfr. PTHC 308-311. Véase también J. M. Millás, "Zubiri y los sacramentos”, op cit., p. 302 , nota 8 .

46. Como ejecutor de sus acciones, el ser humano es agente de ellas, es el "agente de su vida" (HD 77). Pero ejecuta tales acciones en un determinado "contexto vital"; por eso, el hombre también es actor de sus acciones. Ahora bien, ejecutando acciones en un ambiente determinado, él tiene que "optar". Por tanto, ejecutando acciones como agente, actor y optando en ellas, es como el ser humano "realiza" su vida personal. Con ello, precisamente, va "cobrando" su relativa absolutez (HD 78). "Cobrar significa ejecutar acciones frente a todas las cosas" (HD 79); en H. C. Gudiel García, La fe según Xavier Zubiri, op. cit., p. 77. 
Por tanto, la ciencia infusa es la "reflexión de Cristo en la intimidad, a la luz, precisamente, de la voluntad de su Padre". Y unitariamente con la naturaleza de las cosas, "se le manifiesta a Cristo la voluntad del Padre, de quien estas cosas son término". En consecuencia, la ciencia infusa es "el saber del ser [de lo] sustantivo de Cristo como fundador de religión" (PTHC 318) ${ }^{47}$.

Desde esta perspectiva, Cristo tiene la "personalidad de fundador de religión". Este hecho de fundar es justo una acción de Cristo y, como tal, una acción que pertenece a su propia vida. ¿En qué consiste tal acción? Esta podría entenderse como la posibilidad de que Cristo hubiese "instituido una religión" (PTHC 318).

Sin embargo, Cristo eligió otro camino y otra posibilidad para fundar el cristianismo. En efecto, fundar significa que Cristo hace de los seres humanos que le rodean cristianos. Y es que fundar en rigor es plasmar; no se trata de un simple instituir ( $c f r$. PTHC 318). Y plasmar significa "configurar la religión en estos hombres y en aquellos sobre quienes estos hombres van a tener una acción". Se trata de configurar y plasmar "el Yo [de lo] sustantivo del hombre". He aquí en qué consistió la acción fundadora de Cristo desde la perspectiva de su misma acción personal. Es el Hijo del Padre que, con tal acción, nos hace hijos de su mismo Padre. Cristo funda la religión, pues, haciendo de nosotros cristianos. Y su acción fundadora no es una mera institución, sino una "acción efectiva" (PTHC 319).

Este es, en definitiva, el significado de fundar desde el punto de vista del hombre y de Cristo. Habrá que dar un paso más e introducirse en la acción fundante de la persona de Cristo.

\subsubsection{La acción fundante: la muerte y resurrección}

Hemos visto en un primer momento que la fundación del cristianismo es una acción personal de Cristo. A continuación, es menester precisar que esa acción no se diferencia de las "acciones que constituyen" la propia vida personal de Cristo. Y lo que la acción de Cristo confiere a los hombres por medio del cristianismo no es algo que concierne a su realidad sustantiva, sino, ante todo y sobre todo, a la "configuración de un ser". Y se la confiere por una incorporación a la realidad del Verbo encarnado (PTHC 320).

Para clarificar un poco más este segundo paso, Zubiri considera las dos acciones fundamentales en que concluye y culmina la vida personal de Cristo: "Su muerte y su resurrección" (PTHC 320).

47. Sobre el tema puede consultarse también K. Rahner, "Ponderaciones dogmáticas sobre el saber de Cristo y su conciencia de sí mismo", en Escritos de teología, V, pp. 203-222. 


\section{a. La muerte de Cristo $^{48}$}

Para Cristo, su propia muerte, como acción personal, fue un acto de obediencia ( $c f r$. Flp 2, 8). Ahora bien, recordemos que para Zubiri la obediencia tiene su fundamento en la religación. Y además, que la religación subsistente conduce inevitablemente, en Cristo, a un acto de "suprema obediencia" a la voluntad de su Padre (PTHC 321).

La muerte de Cristo tiene, en primer lugar, dos aspectos distintos, pero articulados. Por un lado, es un acontecimiento de su propia "realidad sustantiva". Esto significa que la muerte de Cristo, como la de cualquier ser humano, fue una "desanimación de su organismo o, recíprocamente, una descorporización de su ánima” (PTHC 321) ${ }^{49}$.

Pero, por otro lado, lo que constituye la realidad más profunda de la muerte de Cristo no concierne a su realidad sustantiva, sino fundamentalmente a su ser [de lo] sustantivo. Concierne a ese Yo que la persona de Cristo ha logrado en el transcurso de su vida, y que es propiamente teándrico. Ese Yo es, en rigor, la "figura misma de su ser [de lo] sustantivo". En ella se inscribe efectivamente la muerte de Cristo, y no simplemente en su realidad sustantiva (PTHC 321).

En segundo lugar, la muerte de Cristo se debió también al poder del pecado ${ }^{50}$. Esto fue así porque Cristo se ha incorporado a una humanidad socialmente concreta y, además, "pecadora". ¿Qué significado tiene esta incorporación de Cristo a la humanidad pecadora? (PTHC 321).

La respuesta a esta pregunta sobre el significado de esta incorporación a una humanidad pecadora nos la da, según lo atestigua el Evangelio de Lucas, Cristo mismo cuando dijo a los que venían con Judas a prenderlo en Getsemaní, que

48. Sobre el tema puede verse también C. Duquoc, Jesús, hombre libre, pp. 67-76; G. Gnilka, Jesús de Nazaret. Mensaje e historia, pp. 355-388; W. Kasper, Jesús, el Cristo, pp. 191-205; J. Moltmann, El Dios crucificado, pp. 157-219; y J. Sobrino, Jesucristo liberador, op. cit., pp. 309-334.

49. Para explorar un poco más la "opinión de Zubiri” acerca de la cuestión de la muerte, aquí se remite a su artículo "El hombre y su cuerpo", Asclepio, XXV (1973), p. 8 (PTHC 321, nota 1). Este artículo apareció también en X. Zubiri, Siete ensayos de antropología filosófica, pp. 87-99. Del mismo Zubiri puede verse también Sobre el hombre, pp. 644-671.

50. Según Zubiri, "junto al pecado original y al personal habría que introducir temáticamente, en la teología, el pecado de los tiempos, el pecado histórico. Es el 'poder del pecado' como factor teológico de la historia, y creo esencial sugerir que este poder recibe formas concretas, históricas, según los tiempos. El mundo está en cada época dotado de peculiares gracias y pecados" ("En torno al problema de Dios", en NHD, p. 452). Sobre la "versión zubiriana de las estructuras de pecado", véase J. Antúnez Cid, La intersubjetividad en Xavier Zubiri, Roma, 2006, p. 541. 
era "la hora del poder de las tinieblas" (Lc 22, 53) $)^{51}$. Desde esta perspectiva, encarnarse en una humanidad pecadora significa vivir en una sociedad y en un mundo en el que de una u otra forma existe "el poder de las tinieblas". Estas son expresión del pecado: "Es el poder del pecado" (PTHC 322).

¿Qué entiende Zubiri por poder? En su opinión, poder es precisamente la "dominancia de lo real en tanto que real" 52 . Ese poder tiene que fundarse en algunas "propiedades características que constituyen la realidad en su capacidad

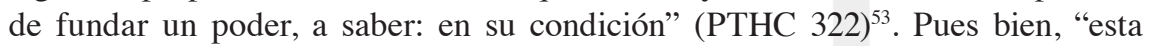
dimensión de realidad en que se funda el poder del pecado es justamente la voluntad de los hombres en malicia" (PTHC 322-323) ${ }^{54}$. Y precisamente porque los seres humanos "están en voluntad de malicia existe en el mundo [...] el poder del pecado" (PTHC 323).

En consecuencia, el hecho de que "Cristo se haya encarnado en una humanidad pecadora significa, por lo pronto, que se ha encarnado en un mundo donde la

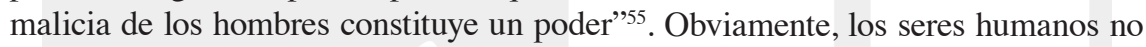
son solo individuos, son también seres sociales que en su "convivencia y coexistencia" van construyendo un mundo ${ }^{56}$. Ciertamente, el mundo no se identifica con cada individuo ni con la suma de todos ellos, pero el mundo tampoco existe fuera de ellos. El mundo tiene ese carácter impersonal de ser un topos $^{57}$. Por eso, "la realidad del mundo es esencial y constitutivamente tópica" (PTHC 323).

Ahora bien, este topos descansa obviamente sobre las personas que en él viven. Pero no solo se trata de un mundo "en que hay unas cosas que tienen vigencia para los individuos", sino sobre todo y radicalmente, de un mundo entendido como principio de ellos. Es decir, es un mundo que lleva a las personas

51. El versículo completo dice: "Estaba yo todos los días en el templo con vosotros y no me pusisteis las manos encima; pero esta es vuestra hora y el poder de las tinieblas" (Lc 22, 53) NBJ. Una "nota exegética" de este versículo puede verse en J. A. Fitzmyer, El Evangelio según san Lucas, IV, Madrid, 2006, pp. 412-413.

52. Cfr. HD 84-91; IRE 195-200 ( $c f r$. PTHC 322, nota 1).

53. Sobre qué es condición y su íntima relación con la respectividad, véase SSV 227-234. También, J. M. Castillo Castillo, Realidad y transcendentalidad en el planteamiento del problema del mal según Xavier Zubiri, p. 11; la tesis, Castillo la formula así: "El mal es una condición de la realidad en respectividad ante el hombre".

54. "La malicia implica un acto de voluntad, mediante el cual el hombre asume un mal intencionalmente" (J. Martín Castillo, Realidad y transcendentalidad, op. cit., p. 54). Sobre el concepto de malicia en Zubiri, véase también SSV 262-267 (PTHC 323, nota 1).

55. Puede verse también A. González, "Dios y la realidad del mal en Zubiri", Estudios Eclesiásticos 266 (1993), pp. 273-315.

56. Sobre el hombre como realidad social véase la amplia exposición de Zubiri en SH 223-341.

57. Cfr. HD 135. 
a vivir, por lo menos inicialmente, como el mismo mundo es (PTHC 323). Por eso no solo se trata de vigencia, sino de un poder: "El poder del mundo sobre los individuos que en él viven”. Es el mundo como poder (PTHC 323-324).

Pues bien, los hombres han ido deponiendo en ese mundo sus pecados. El poder que tiene el mundo en virtud de tal deposición pecaminosa es propiamente el poder del pecado. Por tanto, la "incorporación de Cristo a una humanidad pecadora consiste [...] en vivir en un mundo de pecado" ${ }^{58}$. Esto significa en una u otra forma "estar bajo el poder del pecado". Naturalmente, "Cristo no está bajo el poder del pecado siendo él pecador" $"$. El pecado consiste propiamente en que la persona viva “aversivamente". Pero antes de vivir de ese modo, la persona está inmersa en un "mundo que es un mundo en aversión a Dios, es decir, un mundo de pecado, del poder del pecado"60. El poder del pecado "se cierne sobre la persona de Cristo, sin llegar a su última intimidad radical” (PTHC 324).

Pues bien, el hecho de vivir en ese mundo "en el que existe el poder del pecado pero sin ser personalmente pecador en ninguna forma es aquello que constituyó formalmente la incorporación de Cristo a la humanidad pecadora"61. Y esta incorporación fue precisamente la muerte de Cristo. Esta fue, por un lado, la consecuencia natural del poder del pecado. Pero por otro lado, esa muerte dejó a Cristo libre de todo daño en su propia realidad filial (PTHC 324) ${ }^{62}$.

En tercer lugar, la muerte de Cristo fue la oblación de su vida. En efecto, decíamos que esa muerte le dejó incólume en su "condición de Hijo de Dios, y precisamente en la oblación de su vida" (PTHC 324).

Esa oblación de Cristo tiene tres características. El acatar la voluntad del Padre por parte de Cristo aparece, ante todo, como un acto de "adoración"

58. Una noción del "pecado en el mundo", en J. I. González Faus, Proyecto de hermano. Visión creyente del hombre, Santander, 1991, pp. 243-247.

59. Expresa esta idea de Zubiri san Pablo cuando afirma: "A quien no conoció pecado, le hizo pecado por nosotros, para que viniésemos a ser justicia de Dios en él" (2 Cor 5, 21), NBJ.

60. A modo de conclusión de este apartado, podríamos citar lo siguiente: "Solo se puede comprender radicalmente la esencia del pecado si se capta la relación e interacción mutua entre el pecado como acto del hombre y el pecado como un poder que domina sobre él", (cursivas nuestras); en J. M. Millás, Pecado y existencia cristiana. Origen, desarrollo y función de la concepción del pecado en la teología de Rudolf Bultmann, Barcelona, 1989, p. 254.

61. Sobre la incorporación de Cristo a la humanidad véase también PTHC 65-76.

62. Ciertamente, no lo dejó indemne en su "cuerpo y en su alma" (PTHC 324). 
(PTHC 324) ${ }^{63}$. Además, está el carácter de súplica de Cristo en la cruz: Padre, "perdónalos porque no saben lo que hacen" (Lc 23, 34) (PTHC 324-325) ${ }^{64}$.

La última característica de esta oblación de Cristo consiste en "expiar los pecados de la humanidad". Aquí, expiar significa en concreto el que, unido al poder del pecado, Cristo "ha introducido un nuevo poder: el poder de Dios". Por eso, el acto supremo "de religión en Cristo fue su muerte, porque fue el acto supremo de religión en tanto que Hijo" (PTHC 325).

En este contexto, en cuarto lugar, Zubiri se pregunta "qué fue esa muerte de Cristo como acción fundadora del cristianismo para el resto de los hombres" (PTHC 325).

Para responder a esa cuestión cabe destacar, ante todo, que en la persona de Cristo el poder del pecado tuvo un "límite". Lo tuvo efectivamente porque Cristo "no se hizo pecador por vivir en un mundo de poder de pecado". En el caso del hombre considerado históricamente, en cambio, es un hecho que se hace pecador por vivir en un mundo del poder del pecado. Los seres humanos vivimos "en un mundo en que el poder del pecado transfunde con pecaminosidad intrínseca a la realidad de todos los que en él vivimos". Sean cuales fuesen las razones, es un hecho real que el ser humano se encuentra "internamente abandonado al poder del pecado" (PTHC 325).

En esta perspectiva, hay que añadir que "cada uno de los pecados que la humanidad ejecuta en una o en otra forma va aumentando". O, por lo menos, va consolidando el poder del pecado en esa humanidad. Esto es indudable. Todos los pecados de la humanidad contribuyen al poder del pecado, que se "cierne como elemento integrante del mundo" en que vivimos. El libro del Génesis pone de manifiesto precisamente cómo "el pecado de la humanidad había abarcado a la humanidad entera" ( $c f r$. Gn 6, 12) (PTHC 325).

El poder del pecado, en los pecados que la humanidad va realizando, se va ampliando en modo sofocante en el transcurso de la historia de la humanidad. En este sentido, todos los pecados están incluidos en este poder ( $c f r$. PTHC 326).

63. Sobre el acatamiento véase la anterior nota 26.

64. Además del acatamiento, está la súplica. La súplica es la “'esencia de la oración'. Desde esta perspectiva puede decirse que la oración es propiamente una 'entrega suplicante de la mente a Dios'. El hombre suplica a Dios en las cosas y con las cosas mismas y no fuera de ellas. Por esa transcendencia de Dios en las cosas es posible la oración. Es la entrega como súplica (HD 200)"; en H. C. Gudiel García, La fe según Xavier Zubiri, op. cit., pp. 127-128. Una nota exegética de Lucas 24, 34a , puede verse en J. A. Fitzmyer, El Evangelio según san Lucas, pp. 493-494. 
En quinto lugar, hay que preguntarse además “¿en qué consiste el pecado original y su carácter originante?" ${ }^{65}$. Ante todo, es obvio que no se trata de un pecado que se hereda. Esa es una idea extraña, incluso al pensamiento de san Pablo. Pablo describe la situación del hombre partiendo de Cristo y no de Adán; en efecto, ve a Adán desde Cristo y no a no al revés ( $c f r$. Rm 5, 12). Y esto es fundamental ( $c f r$. Rm 5, 12).

El pecado original tiene para Zubiri su "carácter originante en haber sido el primer pecado de la humanidad, es decir, el pecado que estableció sobre la tierra [...] el poder del pecado". En este sentido, puede afirmarse que "si Adán no hubiese pecado, cualquier otro pecado de los cometidos en la humanidad estaría en esa misma condición. El pecado original estableció el poder del pecado sobre la tierra. Y la sede de este pecado es precisamente el mundo en cuanto tal". Según nuestro autor, el "dominio del poder del pecado consiste en que cada uno de los individuos, que nacemos sumergidos en un mundo de pecado, nos encontramos en la imposibilidad moral de quedar substraídos a él” (PTHC 326).

El pecado original, pues, "es una realidad de orden moral, no es una especie de ingrediente cromosómico que vamos heredando" (PTHC 326-327).

El ser humano se encuentra en la imposibilidad moral de substraerse al pecado original. Esto sucede con el pecado de Adán, y también con el pecado de la humanidad. Pero esto no significa que todos los hombres seamos pecadores. No es que "estemos cometiendo un pecado". Fundamentalmente, se trata de que estamos empecatados (PTHC 327) ${ }^{66}$.

Estar empecatado consiste, según la opinión de Zubiri, en "pertenecer a un mundo en el que existe el poder del pecado y frente al cual, cuando llegue su momento, cada uno de los individuos que ejecuta actos capaces de responsabilidad, moralmente no podrá substraerse al poder del pecado". Por tal razón, "antes de vivir aversivamente en un pecado personal, el hombre vive empecatadamente en un mundo en el que está el poder del pecado cerniéndose sobre cada uno de los individuos, un poder en virtud del cual cada hombre vive privativamente respecto de Dios" (PTHC 327).

De lo anterior se desprende que en su realidad más profunda, el ser humano está íntimamente sometido al poder del pecado; consecuentemente, necesita de salvación o redención (PTHC 327). La redención no conlleva solamente el

65. Aquí, Zubiri presupone lo ya dicho sobre el pecado original al tratar el tema de la creación ( $c f r$. PTHC 226-228). Una presentación teológica del pecado original originante puede verse en L. F. Ladaria, Teología del pecado original y de la gracia, Madrid, 1997, pp. 122-129; J. L. Ruiz de la Peña, El don de Dios. Antropología teológica especial, Santander, 1991, pp. 173-182.

66. Se trata de un término también utilizado por I. Ellacuría, Conversión de la Iglesia al Reino de Dios, San Salvador, 1985, pp. 81-125. 
"perdón moral de los pecados" (PTHC 327-328). En efecto, para que "el perdón tenga un sentido real y efectivo tiene que producir una transformación" interior en la persona perdonada. El perdón consiste fundamentalmente en esa transformación intrínseca que Cristo realiza en el ser humano. Y "esa transformación consiste en que el poder del pecado ha quedado supeditado al poder de Dios". Este es el significado de la redención (PTHC 328).

Finalmente, en sexto lugar, el poder de Dios es un poder radicalmente concedido "al ser del hombre que no producirá sus efectos más que cuando este hombre vaya ejecutando actos personales". Por tanto, la muerte de Cristo fue para él esa "identidad numérica entre la vida personal de Cristo y la transformación del hombre". Este "ha sido plasmado como una realidad en el poder de Dios, precisa y formalmente por el acto mismo numéricamente con que Cristo dio su vida en la cruz" (PTHC 328).

En ese sumo "acto de religión que fue para él su muerte, Cristo plasma el ser [de lo] sustantivo de todos los demás hombres". Y lo plasma real y efectivamente. Con su muerte, Cristo pone en modo real y efectivo el ser del hombre en el ámbito del poder de Dios. En este sentido, el ser humano está liberado del "poder del pecado, por lo menos como un poder subyugante" (PTHC 328).

En consecuencia, los hombres tenemos siempre en nuestro propio ser la posibilidad de ser, por nuestra incorporación a Cristo, realidades humanas que estemos "más bajo el poder de Dios que bajo el poder del pecado" (PTHC 329).

\section{b. La Resurrección de Cristo ${ }^{67}$}

El segundo acto de la vida de Cristo, íntimamente ligado al de su muerte, se considera aquí desde el significado de la Resurrección de Cristo en sí misma, y desde lo que la Resurrección es para los seres humanos en cuanto acto fundador del cristianismo ( $c f r$. PTHC 329).

Ante todo, Zubiri parte del célebre dato en la Resurrección sobre el tercer día. Bíblicamente, se trata del "tercer día a propósito de la muerte y de la vida" (cfr. Os 6, 2; Mt 12, 39-41; 16, 4; Lc 11, 29-32). Afirmar que "va a resucitar al tercer día es decir que va a resucitar de una manera muy rápida, y que ese poco tiempo es el único en que se concede vigencia al poseer del mal" (PTHC 329).

67. Cfr. PTHC 238-241. Una perspectiva teológica del tema, en G. O. Collins, Jesús resucitado. Estudio histórico, fundamental y sistemático, Barcelona, 1988; C. Duquoc, Jesús, hombre libre, op. cit., pp. 77-91; W. Kasper, Jesús, el Cristo, Salamanca, 2002, pp. 209-264; K. Rahner, Curso fundamental sobre la fe, pp. 313-317; 322-332. También, A. Torres Queiruga, Repensar la Resurrección, Madrid, 2003; y J. Sobrino, La fe en Jesucristo. Ensayo desde las víctimas, pp. 25-209. 
b.1. La Resurrección de Cristo en sí misma. Ante todo, veamos en qué consiste la Resurrección de Cristo considerada en sí misma. Aquí se clarifica de entrada que esta no es la "reanimación de un cadáver". Y no lo es por tres razones. La primera, porque lo esencial en la Resurrección no consiste en afirmar que Cristo "estuvo muerto, sino que está vivo". Pero, además, con su Resurrección, Cristo está vivo, pero no como lo estuvo Lázaro, sino que está vivo para siempre. "El poder del pecado y de la muerte no tendrá ya acceso sobre Cristo". Es una vida diferente. Y, finalmente, porque ese Cristo que está vivo "es una vida en plenitud de poder" (PTHC 330).

A continuación, Zubiri precisa un poco más la Resurrección de Cristo en los términos siguientes.

En primer lugar, la Resurrección de Cristo consiste, ante todo, en que se va a otro mundo, donde, a la derecha del Padre, tiene precisamente la "plenitud de poderes en una vida que nunca le será arrebatada" (PTHC 330).

En segundo lugar, además, Cristo resucita con su cuerpo. Obviamente, no se trata de un cuerpo ordinario. Es más bien lo que san Pablo llama un "cuerpo espiritual" (1 Co 15, 44) ${ }^{68}$. Es, en definitiva, la "condición de un cuerpo glorificado" (cfr. Jn 20, 19-29) (PTHC 330). El lugar que le corresponde a Cristo resucitado es precisamente el "centro de la creación y de la historia". La Resurrección de Cristo no es, pues, la reanimación de un cadáver, sino que radicalmente se trata de la "transformación interna de un cadáver que sitúa a Cristo en el otro mundo" (PTHC 331).

No obstante, el cuerpo del resucitado tiene caracteres de "corporeidad". Los tiene porque, según la propia perspectiva de Zubiri, la "función primaria de la corporeidad no es precisamente el tener carácter carnal". Es decir, el cuerpo tiene, ante todo, la "condición de ser la actualidad presencial de aquello de quien es cuerpo"69. Además, porque el cuerpo tiene que conferir a "aquello de que es cuerpo una interna consistencia" ${ }^{70}$. Y, finalmente, porque tiene que "expresar corpóreamente lo que eso de quien es cuerpo constitutivamente es" (PTHC 331) $)^{71}$.

Pues bien, afirmar que "Cristo resucitado tiene el mismo cuerpo significa que tiene la misma actualidad, la misma consistencia y la misma expresión". Naturalmente, esto no significa que tenga una "mismidad por identidad estructural

68. Un comentario a este versículo, en G. Barbaglio, La prima lettera ai Corinzi, pp. 842-846. También, J. Sánchez Bosch, Escritos paulinos, p. 214.

69. Véase además HD 40.

70. Puede verse también PFHR 252-253.

71. En "El hombre y su cuerpo", op. cit., pp. 3-15, "Zubiri expone sistemáticamente su concepción de la corporeidad" (PTHC 331, nota 1). 
en su realidad sustantiva". Se trata, como se dijo, de una "mismidad de presencia, de consistencia y de expresión" ( $c f r$. Jn 20, 27) (PTHC 331).

En definitiva, la Resurrección de Cristo fue la "transfiguración gloriosa de un cuerpo que confiere actualidad, consistencia y expresión a lo que es Cristo" (PTHC 332).

$\mathrm{Y}$, en tercer lugar, este Cristo resucitado que va a otro mundo, sin embargo se manifiesta en este mundo para ser reconocido: es el tema del reconocimiento. Justo lo que pone de relieve san Pablo en el relato "más antiguo" de las apariciones, con el verbo en voz pasiva: fue visto (1 Cor 15, 5-8 $)^{72}$. Esta expresión paulina quiere decir, según Zubiri, que Cristo se hizo ver. Aquí no se trata de una ilusión subjetiva, sino de la "mostración" concreta y real de Cristo, cuya iniciativa personal está en él (PTHC 332).

Es Cristo mismo que "se hace ver en su condición de cuerpo glorioso. Y se hace ver a quien quiere, cuando quiere y como quiere" (PTHC 332-333). Pero "se hace ver para ser reconocido" (PTHC 333).

Ahora bien, este reconocimiento que tienen los hombres de Cristo resucitado es lento y gradual. Es lo que el Evangelio de san Lucas 24, 13-35, entre otros, pone efectivamente de manifiesto ${ }^{73}$. No se trata del reconocimiento inmediato de la fisonomía de alguien por la calle. El reconocimiento de Cristo es, pues, un reconocimiento progresivo ( $c f r$. PTHC 333).

Además de la iniciativa de Cristo y su carácter progresivo, las apariciones de Cristo resucitado están encuadradas propiamente en la misión de difundir el cristianismo en el mundo ( $c f r$. PTHC 334) ${ }^{74}$.

b.2. La Resurrección de Cristo desde el ser humano. Expuesta la Resurrección de Cristo en sí misma, también hay que considerar el significado que tuvo para los hombres.

En primer lugar, aquí se pretende observar la Resurrección de Cristo en cuanto que es "un acto numéricamente uno de plasmación del cristianismo en cada una de las personas a las que llega" (PTHC 334).

Y se considera este significado desde lo que san Pablo describe en la carta a los Romanos 6, 3-11, sobre el bautismo ${ }^{75}$. Lo que ahí quiere expresar el Apóstol,

72. Un análisis detallado de cada uno de estos versículos de la Primera carta a los Corintios, en G. Barbaglio, La prima lettera ai Corinzi, op. cit., pp. 811-815.

73. Sobre los discípulos de Emaús, véase J. A. Fitzmyer, El Evangelio según Lucas, IV, op. cit., pp. 570-599.

74. Respecto a ese tema, véase Mateo 28, 16-20; Marcos 16, 15-16.

75. Un análisis exegético de Romanos 6, 1-14 puede verse en la reciente obra de X. Alegre Santamaría, Carta a los Romanos, Navarra, 2012, pp. 189-201; véase también J. Gnilka, Teología del Nuevo Testamento, pp. 123-127. 
en opinión de Zubiri, es que "con la muerte de Cristo hemos muerto nosotros al pecado y hemos pasado justamente a una vida distinta y superior" ${ }^{\text {"76 }}$. Es la plasmación de este paso de la tierra a la derecha del "Padre (en que ha consistido formalmente la Resurrección) en el ser de cada uno de los hombres". Es decir, "la Resurrección de Cristo es en sí misma, como acción personal de Cristo, una plasmación del ser del hombre". Y lo que en esa plasmación se produce es precisamente que el ser del hombre, que era "aversivo a Dios" por estar bajo el poder del mundo, se convierte ahora en un ser "conversivo hacia Dios". En palabras de san Pablo, en ser una "creación nueva" (2 Cor 5, 17; Gál 6, 15). Es el "hombre nuevo" (cfr. Ef 2, 5; 4, 24; Col 3, 10). El hombre, según san Pablo, "se reviste (...) de Cristo" (Rm 13, 12-14), por incorporación (PTHC 334) ${ }^{77}$.

En segundo lugar, ese revestimiento consiste precisamente en lo que sucedió en la Resurrección. En esta perspectiva, Zubiri dice que para san Pablo, hay un “cuerpo psíquico", animado, y un "cuerpo espiritual” (1 Cor 15, 44). El primero es terrestre y es el cuerpo de Adán. El segundo es celeste y es justo el cuerpo de Cristo ( $c f r .1$ Cor 15, 47), al que Pablo llama "espiritual" porque es "vivificante" (cfr. 1 Cor 15, 45) (PTHC 335) ${ }^{78}$.

En cambio, aclara Zubiri, el "psiquismo es para san Pablo pura y simplemente animante". En virtud de su Resurrección, el cuerpo de Cristo nos da un "espíritu que no teníamos por Adán, del cual no tendríamos sino por animación. El cuerpo de cada cual no es por esto transformado, pero sí queda radicalmente destinado a tener, justamente en la resurrección de los muertos, el carácter pneumático que tiene el cuerpo de Cristo". Por tanto, la Resurrección de Cristo es fundamentalmente la enunciación - las arras, como dice san Pablo (cfr. 2 Cor 1, 22; 5, 5) "de lo que real y efectivamente le acontece [al cuerpo del hombre] en virtud de lo que Cristo le ha dado" (PTHC 335).

76. Subrayando la "prioridad de la cruz", X. Alegre expresa que "el pensamiento teológico de Pablo no gira en torno al bautismo, sino al crucificado, quien, como resucitado que es, determina el futuro y el presente; y gira en torno a las consecuencias que se deducen de esa acción salvífica de Dios" (para la soteriología, para la Ley de Moisés, para Israel y para la existencia y esperanza cristianas); en X. Alegra Santamaría, Carta a los Romanos, op. cit., p. 194. Sobre el bautismo como "experiencia de la muerte", véase también J. M. Castillo, Símbolos de libertad. Teología de los sacramentos, Salamanca, 1992, pp. 192-197.

77. Véase X. Alegre Santamaría, Carta a los Romanos, op. cit., pp. 321-322.

78. Un comentario clarificador de 1 Corintios 15, 44-45.47, en sus páginas respectivas, en G. Barbaglio, La prima lettera ai Corinzi, op. cit., pp. 843-846; 846-848; y 851-853. 
Ahora bien, en tercer lugar, esa plasmación en virtud de la Resurrección de Cristo se produce por la regeneratio (Tit 3, 5) ${ }^{79}$. Pero esta regeneración no es la plasmación ad extra de la vida trinitaria, sino que más bien consiste en dar a dicha plasmación trinitaria la "capacidad de estar ella misma dentro del poder de Dios". La regeneratio es, entonces, una "re-generación” (PTHC 335).

Eso significa, ante todo, que al ser del hombre lo extraen de la situación de estar dominado por el poder del pecado, para quedar sujeto al ámbito del poder de Dios. En esto consiste realmente la "Resurrección de Cristo como plasmación del cristianismo en el espíritu de los hombres". Por lo tanto, lo que "pone en el regenerado es precisamente el poder de Dios" en el ser humano. Y ese poder de Dios en el hombre es, en esta perspectiva, lo que aquí se llama xáris, gracia $\left(\right.$ PTHC 336) ${ }^{80}$.

Aquí hay que clarificar, en cuarto lugar, que la gracia no es algo que le viene de fuera al ser humano. En opinión de Zubiri, gracia "es la inserción intrínseca dentro de la plasmación en que trinitariamente consiste la realidad del hombre (aunque esté condenado), mientras está en este mundo". En esa plasmación se inscribe precisamente el poder dinámico de Dios. En realidad, la gracia es el poder de Dios en el ser humano, y en virtud de ese poder va construyendo su propio "ser [de lo] sustantivo". Ese poder de Dios en los hombres los "hace ser deiformes". Y no es un auxilio extrínseco, sino que la "Resurrección de Cristo ha plasmado en el seno del espíritu del hombre, de una manera [...] espiritual, la presencia de esa Trinidad en cuya plasmación consiste la realidad formal del hombre, como fuente de ese poder de Dios" en cada ser humano. En virtud de ello, los hombres merecen ser llamados "hijos de Dios" (PTHC 336).

Por tal razón, la vida de la gracia no es una experiencia psicológica. Propiamente, la vida de la gracia es una "experiencia moral vivida a la luz de la fe. En este sentido, es una experiencia teologal" ${ }^{\prime 1}$. Experiencia que el hombre va teniendo en el transcurso de "una vida o, por lo menos, de períodos de ella. Es lo moral en fe" (PTHC 337).

79. Dice Tito 3, 5: "Él nos salvó no por obra de justicia que hubiésemos hecho nosotros, sino según su misericordia, por medio del baño de regeneración y de renovación del Espíritu Santo"; la cursiva es nuestra, NBJ. Véase también PFHR 174 y PTHC 352.

80. Una perspectiva teológica de la gracia puede verse en L. F. Ladaria, Teología del pecado original y de la gracia, op. cit., pp. 133-301; J. L. Ruiz de la Peña, El don de Dios, op. cit., pp. 337-369.

81. Sobre la experiencia de Dios y la gracia puede verse El hombre y Dios, pp. 319-334 (PTHC 337, nota 1). 


\section{c. Unidad de la muerte y Resurrección de Cristo $^{82}$}

La fundación del cristianismo, pues, consiste en esos dos actos concretos de la muerte y la Resurrección de Cristo, considerados como los actos supremos de su vida. Estos son la respuesta a la cuestión sobre "cómo se realiza la fundación del cristianismo". Son las propias acciones de la vida personal de Cristo las que "por incorporación de la humanidad han plasmado en los hombres aquello que es su último y radical sentido" (PTHC 337).

Ahora bien, aquí se ha hablado de dos actos. Pero la verdad es que jamás el Nuevo Testamento, cuando temáticamente se refiere al "verdadero problema de la redención del hombre, habla de dos actos, sino de uno: fue crucificado y resucitado". Esa "y" que une ambos actos no es una "y" copulativa. Más bien expresa la "unidad intrínseca de dos actos aparentemente tan distintos como son la muerte por crucifixión y la resurrección" 83 . En rigor, se trata de un acontecimiento real que coloca el ser del hombre "bajo el poder de Dios por una regeneración interna en la gracia y por incorporación” (PTHC 337).

En definitiva, Cristo funda el cristianismo haciendo cristianos. Y las acciones personales de la vida de Cristo que posibilitaron tal fundación fueron precisamente su muerte y Resurrección. En realidad, se trata del acto real y unitario de su muerte y Resurrección. En virtud de dicho acto, Cristo hace de los seres humanos cristianos (cfr. PTHC 338).

Ahora bien, estos actos de la vida de Cristo no acontecieron una única vez. En efecto, son actos que se vuelven a realizar continuamente en el transcurso de la historia de la humanidad. Pues bien, la consideración unitaria de las siguientes tres dimensiones: "El acto que es una acción personal de Cristo, que esa acción personal de Cristo sean las acciones de su propia vida y que esas acciones de su propia vida se repitan constantemente es lo que constituye la definición plenaria" de lo que Zubiri entiende por sacramento (PTHC 338) ${ }^{84}$.

\section{Conclusión}

Finalizada esta exposición descriptiva en torno a la encarnación del Verbo de Dios en la perspectiva zubiriana, estamos en condiciones para recoger y valorar algunas de las ideas e intuiciones más significativas hasta aquí presentadas.

82. Una aproximación teológico-unitaria del tema, en K. Rahner, Curso fundamental sobre la fe, pp. 311-334; concretamente, p. 313.

83. La misma idea en PTHC 350-351.

84. Es lo que nos pone a las puertas de la tercera y última cuestión sobre la obra de Cristo: la repetición de las acciones de Cristo. Dada la extensión y la relativa autonomía de ese tema, hemos optado por presentarlo en otro momento. 
En primer lugar, abordamos sucintamente la exposición neotestamentaria, con el objeto de clarificar de entrada lo expuesto en el texto revelado sobre la encarnación del Verbo de Dios. Y para explicar las primeras ideas sobre Cristo, consideramos Hechos de los Apóstoles 2, 22-36 y la Carta a los Romanos 1, 3-4. Ambos textos bíblicos expresan los aspectos centrales de una "cristología primitiva".

Esa cristología primitiva fue desarrollada por los cuatro evangelistas, exponiendo cada uno a su modo, su propio logos de Cristo. Además, en las cartas paulinas, el logos de Cristo consiste en que en él está la plenitud del Verbo y de la creación.

En segundo lugar, la comunidad eclesial precisó y clarificó la filiación divina de Cristo en el contexto teórico de la razón griega, que obviamente condicionó su respuesta.

En ese contexto, la Iglesia afirma que Cristo es Hijo de Dios, y manifestación verdadera de Dios. Además, expresó que la humanidad de Cristo y la divinidad del Verbo es cada una perfecta; son realidades completas y constituyen una sola filiación divina. Ahora bien, esta filiación singular consiste en que Cristo es el Verbo mismo. Es decir, la realidad de Cristo es divina físicamente y no por adopción. Se trata de unidad física. Por eso, filiación divina es propiamente "unidad física".

Finalmente, se dijo que la unidad física del Hijo de Dios consiste en que Jesucristo es perfecto Dios y perfecto hombre. Y se definió la unidad de la naturaleza divina y la naturaleza humana en la única persona del Verbo encarnado. Contra el monotelitismo, se definió la existencia de dos voluntades en Cristo.

Considero un mérito indiscutible de Xavier Zubiri el haber recogido, aunque sea sucintamente en su estudio filosófico-teológico, el dato revelado neotestamentario sobre el Hijo de Dios, como punto de partida para su propia conceptuación sobre la encarnación. Igualmente significativa es la consideración de los momentos fundamentales en la reflexión que la tradición eclesial ha realizado de la encarnación del Verbo de Dios. Ambos aspectos contextuales aparecen como puntos de apoyo creíbles y adecuados para la exposición propiamente zubiriana sobre la encarnación. Ellos posibilitan y ponen de relieve cómo la tradición eclesial ha ido gradual e históricamente clarificando y precisando en qué consiste la fe en Jesucristo, el Hijo de Dios.

En tercer lugar, se conceptuó zubirianamente la encarnación del Verbo de Dios, desde las cuestiones sobre la persona, la vida y la obra de Cristo.

Ante la primera pregunta sobre quién es la persona de Cristo, se respondió desde el momento del ser de lo sustantivo de Cristo, el Yo, que se ha ido configurando y construyendo en virtud de sus actos, en el transcurso de su vida. Es 
una construcción dinámica e histórica del Yo. Además, ese Yo consiste en ser su verdad real que lo realiza como Hijo de Dios; él es la verdad real del Padre. La realidad sustantiva de Cristo, en cambio, se consideró en el ámbito de la Trinidad, presentando los distintos grados de presencia de la plasmación ad extra de la vida trinitaria. Ahí se subrayó que hay un grado mucho más hondo y radical de una verdadera realidad filial, en virtud de la cual la persona física del Verbo es inmanente a la realidad humana. Y recíprocamente al hijo de María le es inmanente la realidad divina. Por tanto, la realidad de Cristo es fundamentalmente trinitaria.

El Hijo de Dios se sabe como tal por una experiencia vital de configuración de su ser de lo sustantivo, es decir, en el ejercicio mismo de su $m e$, de su $m i$ y de su Yo. Esto posibilitó una mejor comprensión de la posición del Verbo encarnado en la creación, afirmando que consiste en ser la imagen real de Dios y el paradigma de toda esencia abierta.

En la segunda cuestión sobre la vida personal de Cristo, comenzamos diciendo que su vida sobre la tierra es en sí misma un misterio; es un verdadero problema que queda planteado por la propia vida de Cristo. La biografía de Jesucristo consiste en ir logrando su ser de lo sustantivo, en medio de las circunstancias internas y externas, en que esa realidad sustantiva construye su vida. Se trata de un verdadero crecimiento de la personalidad de Cristo, mientras que su personeidad es consustancial a Dios.

Cristo realiza su biografía desde la fundamentalidad de su ser de lo sustantivo. Es decir, siendo la religación, la revelación y la sacralidad subsistentes. La obediencia de Cristo encuentra su raíz y fundamento en Cristo como religación subsistente; su biografía consiste justo en el despliegue experiencial de dicha religación. Pero Cristo también es revelación subsistente, porque es la manifestación de su filiación y de lo que es Dios en cuanto Padre. La humanidad de Cristo, además, es sagrada, es sacramento subsistente. Por eso, Cristo hizo signos, y al hacerlos pidió una adhesión personal, esto es, fe.

Por tanto, la religación subsistente, la revelación en acto y la sacramentalidad subsistente, unitariamente consideradas, constituyen el sentido último y radical de la biografía de Cristo. Este es el sentido de su biografía.

En el tercer y último problema sobre la obra de Cristo, se respondió que esa biografía del Hijo de Dios en intimidad con su Padre es la que se transmitió, por la tradición, a sus seguidores inmediatos. De ahí que la razón formal de la encarnación sea la deiformidad humana; para esto funda Cristo la religión. La fundación del cristianismo consistió radicalmente en una acción personal de plasmación realizada por Cristo. Por eso, fundar significa que Cristo hace de los hombres y mujeres que le rodean, cristianos. De esa manera, es el Hijo de Dios quien nos hace hijos del Padre, en el Hijo. 
La acción suprema en virtud de la cual Cristo fundó el cristianismo es la de su muerte. Esta fue un acontecimiento de su propia realidad sustantiva y de su Yo, pero también fue un hecho que se debió al poder del pecado. La muerte de Cristo fue, además, la oblación de su vida, cuyas características son el acatamiento, la súplica y el expiar los pecados de la humanidad. Una humanidad que fundamentalmente está empecatada.

Ligada a su muerte aparece la Resurrección de Cristo, como segundo acto supremo fundador del cristianismo. Lo fundamental de la Resurrección consiste en que Cristo está vivo para siempre en plenitud de poder. Ahora bien, Cristo resucita con su cuerpo, un cuerpo que tiene carácter de corporeidad. Esto significa que el cuerpo del resucitado tiene una mismidad de actualidad, de consistencia y de expresión. Finalmente, Cristo resucitado se manifiesta en este mundo para ser reconocido, y sus apariciones tienen la misión de difundir el cristianismo en el mundo. La Resurrección de Cristo es un acto de plasmación del cristianismo en cada uno de los seres humanos a los que llega.

En definitiva, la fundación del cristianismo se realiza con la muerte y Resurrección de Cristo como los actos supremos de su vida, considerados unitariamente. En efecto, se trata del acto unitario de muerte y Resurrección de Cristo.

Considero de gran interés y de innegable valor el que desde su propia filosofía Zubiri haya logrado interpretar aguda y coherentemente, la encarnación del Verbo. No cabe duda de que esta manera de pensar es expresión del vigor y de la originalidad que se desprenden de su propio pensamiento. Se trata de una filosofía que no se ha hecho prisionera de la mera filosofía, sino que ha mostrado una capacidad significativa de incursionar y abrirse creativamente a problemas teológicos concretos, tal como hemos podido constatar con el tema de la encarnación del Verbo de Dios. Con lo cual tanto la filosofía como la teología salen enriquecidas, y su íntima relación se vuelve un reto constante para abordar problemas reales, históricos y concretos que merecen una seria fundamentación teórica.

\section{Siglas usadas para la obra de Zubiri}

HD: $\quad$ Hombre y Dios, Madrid, $1998^{6}$.

IRA: Inteligencia y razón, Madrid, 1983.

IRE: Inteligencia sentiente. Inteligencia y realidad, Madrid, $1991^{4}$.

NHD: Naturaleza, historia, Dios, Madrid, $1999^{11}$.

PFHR: El problema filosófico de la historia de las religiones, Madrid, 1994.

PTHC: El problema teologal del hombre: Cristianismo, Madrid, 1997.

SH: $\quad$ Sobre el hombre, Madrid, $1998^{1 \mathrm{re}}$.

SSV: $\quad$ Sobre el sentimiento y la volición, Madrid, 1993. 